\section{TÀI LIÊU THAM KHẢO}

1. Pannucci CJ, Bailey SH, Dreszer G và các cộng sứ. (2011), "Validation of the Caprini risk assessment model in plastic and reconstructive surgery patient", J Am Coll Surg, 212(1), 105-12.

2. Caprini JA (2010), "Risk assessment as a guide for the prevention of the many faces of venous thromboembolism", The American Journal of Surgery, 199(1), 3-10.

3. Bùi Mỹ Hanh, Đào Xuân Thành, Nguyễn Hoàng Hiệp và các cộng sự. (2019), "Khảo sát một số yếu tố nguy cơ của hưyêt khối tî́nh mạch ở người bệnh sau phâuu thuật chấn thương chỉnh hình", Nghiên cứu y học, 121(5), 81-88.

4. Bùi Mỹ Hanh, Đoàn Quốc Hưng và Hoàng Thi Hồng Xuyến (2019), "Ứng dụng thang điểm caprini hiêu chỉnh trong đánh giá nguy cơ huyết khối tĩnh mạch trên người bệnh phẩu thuật mạch máu",
Nghiên cứu y học, 122(6).

5. Bùi Mỹ Hanh, Dương Tuấn Đức và Trân Tiến Hưng và cộng sự (2019), "Chi phí điều trị trự̛́c tiếp biến chứng huyết khối tĩnh mạch sau phẩu thuât 30 ngày ", Nghiên cứu Y hocc, 123(7), 86-93.

6. Scarpa RM, Carrieri G, Gussoni G va các cộng sư. (2007), "Clinically overt venous thromboembolism after urologic cancer surgery: results from the @RISTOS Study", Eur Urol, 51, 130-135.

7. Kanchan B, Anitha M, Mohsina S và các công sư. (2016), "Assessing the risk for development of Venous Thromboembolism (VTE) in surgical patients using Adapted Caprini scoring system", Int J Surg, 30, 68-73.

8. Petralia GA và Kakkar AK (2008), "Venous thromboembolism prophylaxis for the general surgery patient: where do we stand?", Semin Respir Crit Care Med, 29, 83-89.

\title{
KẾT QUẢ ĐIỀU TRI VIÊM PHỔI NĂNG Ở TRẺ TỪ 2 THÁNG ĐẾN 5 TUỔI TẠI BỆNH VIỆN BÊ̂NH NHIỆT ĐỚI THÀNH PHỐ HỒ CHÍ MINH
}

Ngô Minh Xuân*

\section{TÓM TẮT}

Muc tiêu: Xác đinh tỉ lê các đăc điểm điều trị và kết quả điều trị; Xác định các yếu tố liên quan đến kết quả điều trị viêm phổi năng ở trẻ từ 2 tháng đến 5 tuổi tại Bệnh viện Bệnh Nhiệt Đới Thành phố Hồ Chí Minh. Đối tượng, phương pháp: Bệnh nhi từ 2 đến 59 tháng được chẩn đoán viêm phổi cộng đồng nặng và điều trị tại khoa Nhi $D$ (khoa hô hấp) Bệnh viện Bệnh Nhiệt Đới từ tháng 10/2019 đến tháng 10/ 2020. Đánh giá kết quả điều trị sau 48 giờ nhập viện. Kết quả: Kháng sinh ban đâu: Ceftriaxone $92,8 \%$, Cefoperazon/ Sulbactam (6\%), phối hợp Ceftriaxone + Vancomycin (1,2\%). Diến tiến đáp ứng kháng sinh ban đầu: đáp ứng 95,2\%. không đáp ứng 4,8\%, phải thêm hoăc đổi kháng sinh. Kết quả điều trị: Thành công $86,9 \%$, thất bại $13,1 \%$. Các yếu tố liên quan đến kết quả điều tri: Trẻ có bênh nền có tỉ lê điều trị thành công thấp hơn nhóm khổng có bệnh nền $(O R=17,4$, $\mathrm{P}<0,05)$. Trẻ có tiền căn tiếp xúc với người ho/ sổ mũi trong tuần qua có tỉ lệ điều trị thành công thấp hơn nhóm không tiếp xúc $(O R=9, P<0,05)$. Kết luân: Viêm phổi trẻ em cần chẩn đoán và điêuu trị sớm nhằm giảm tỉ lệ biến chứng và tử vong.

Tư khoá: viêm phổi nặng, kháng sinh, biến chứng

\section{SUMMARY \\ TREATMENT RESULTS OF SEVERE PNEUMONIA IN CHILDREN AGED 2}

\footnotetext{
*Trường Đại học Y Phạm Ngọc Thạch, Tp Hồ Chí Minh Chịu trách nhiệm chính: Ngô Minh Xuân

Email: xuanlien62@pnt.edu.vn

Ngày nhận bài: 10.3.2021

Ngày phản biên khoa học: 28.4.2021

Ngày duyệt bài: 11.5.2021
}

\section{MONTHS TO 5 YEARS AT THE HO CHI MINH CITY TROPICAL DISEASES HOSPITAL}

Objectives: To review the treatment characteristics and treatment results of severe pneumonia in children aged 2 months to 5 years at the Ho Chi Minh city Tropical Diseases Hospital; and explore the related factors to the outcomes. Subjects and methods: Pediatric patients aged 2 to 59 months were diagnosed with severe communityacquired pneumonia and treated at Pediatrics Department D (respiratory department) of Ho Chi Minh city Tropical Diseases Hospital from October 2019 to October 2020. Evaluation of treatment results after 48 hours of admission. Results: Initial antibiotics: Ceftriaxone 92.8\%, Cefoperazone/ Sulbactam $(6 \%)$, combination of Ceftriaxone + Vancomycin $(1.2 \%)$. Progression of initial antibiotic response: $95.2 \%$ response. do not respond $4.8 \%$, must add or change antibiotics. Treatment results: Success $86.9 \%$, failure $13.1 \%$. Factors related to treatment outcome: Children with underlying disease have a lower success rate of treatment than the group without underlying disease $(\mathrm{OR}=17.4, \mathrm{P}<0.05)$. Children with a history of contact with a cough/runny nose in the past week had a lower success rate than the non-contact group $(\mathrm{OR}=9, \mathrm{P}<0.05)$. Conclusion: Pediatric pneumonia requires early diagnosis and treatment to reduce morbidity and mortality.

Keywords: severe pneumonia, antibiotics, complications.

\section{I. ĐĂT VẤN ĐỀ}

Viêm phổi là một trong những nguyên nhân hàng đầu gây tử vong ở trẻ 1-59 tháng. Năm 2015 có 920.136 trẻ em dưới 5 tuổi tử vong vì viêm phổi, chiếm $16 \%$ tổng số ca tử vong của 
trẻ em dưới 5 tuổi. Việt Nam là một trong 15 quốc gia có số lượt mẳc viêm phổi cộng đồng cao nhất toàn cầu [6].

Trẻ em có thể được bảo vệ khỏi viêm phổi, có thể được ngăn ngừa bằng các can thiệp đơn giản, và được điều trị với chi phí thấp. Chẩn đoán viêm phổi trên lẩm sàng không khó khăn nhưng làm sao để biết được tác nhân gây bênh vẫn còn là một vấn đề. Nguyên nhân gây viêm phổi bao gồm virus, vi khuẩn và nấm. Đa số trên lâm sàng điều trị viêm phổi theo tác nhân gây bệnh chủ yếu dựa vào lứa tuổi. Có nhiều công trình nghiên cứu trên thế giới và tại Việt Nam đã thực hiện về viêm phổi cộng đồng cho thây bệnh cảnh lâm sàng trong viêm phổi có nhiều thay đổi do sự thay đổi của tác nhân gây bênh viêm phổi không những về độc lực mà còn về mức độ kháng thuốc và sự nhạy cảm của kháng sinh. Sự khác biệt về địa dư, môi trường sinh sống, kinh tế xã hồi và yếu tố thời gian có thể tao nên sự khác biệt về các chủng vi sinh gây bệnh viêm phổi và độ nhạy cảm kháng sinh ở trẻ em [4].

Thực tế trên lâm sàng chúng ta không thể phân biệt chắc chắn vi trùng hay siêu vi dựa vào triệu chứng hay X-quang phổi phổi [2]. Tại bệnh viện Bệnh Nhiệt Đới, tất cả các ca viêm phổi nặng đều dùng kháng sinh ban đầu theo kinh nghiệm, chưa được thực hiện kỹ thuật hút dịch khí quản qua đường mũi để định danh vi khuẩn. Trong những năm qua, hâu hết các tác giả nghiên cứu tập trung vào vấn đề kháng thuốc của vi khuẩn, rất ít nghiên cứu đề cập đến tác nhân siêu vi. Trên cơ sở đó, chúng tôi tiến hành đề tài này nhằm: Xác định tỉ lệ các đặc điểm điều trị và kết quả điều trị; Xác định các yếu tố liên quan đến kết quả điều trị.

\section{II. ĐỐI TƯợNG VÀ PHƯƠNG PHÁP NGHIÊN CỨU}

Bệnh nhi từ 2 đến 59 tháng được chẩn đoán viêm phổi cộng đồng nặng và điều trị tại khoa Nhi D (khoa hô hấp) Bệnh viện Bệnh Nhiệt Đới từ tháng 10/2019 đến tháng 10/ 2020.

Tiêu chuẩn chẩn đoán viêm phổi cộng đồng nặng lúc nhập viện theo WHO [7]: Viêm phổi cộng đồng là các trường hợp VP xảy ra ở ngoài bệnh viện hoặc trong vòng 48 giờ đâuu tiên sau khi nhập viện. Lâm sàng: ho hoặc khó thở kèm theo ít nhất một trong các dấu hiệu sau: Thở co Iõm lồng ngực; Phập phồng cánh mũi; Thở rên (ở trẻ nhũ nhi); Không đủ tiêu chuẩn của viêm phổi rất nặng. Có thể có thêm một vài hoặc tất cả triệu chứng của viêm phổi như: thở nhanh, phế âm giảm, tiếng vang phế quản, ran nổ, hội chứng ba giảm, hội chứng đông đặc, tiếng cọ màng phổi. Và $X$ quang phổi: có hình ảnh tổn thương nhu mô phổi (thâm nhiếm phế nang và hoặc thâm nhiễm mô kẽ và hoặc đông đặc).

Tiêu chuẩn loại trừ: Bệnh nhi viêm phổi cộng đồng nặng đã nhập viện điều trị ở tuyến trước.

Đánh giá kết quả điều trị [3]: (1) Thất bại điều trị: được đánh giá sau 48 giờ nhập viện điều trị. Có bất kỳ dấu hiệu nào sau đây: Không cải thiện hoặc xấu đi mức độ suy hô hấp; Xuất hiện bất kỳ dấu hiệu nguy hiểm toàn thân nào; Xuất hiện bất kỳ biến chứng nào: tràn khí màng phổi, tràn dịch màng phổi, áp xe phổi, nhiễm trùng huyết, sốc nhiễm trùng. (2) Thành công: đánh giá sau 48 giờ nhập viện điêuu trị. Thỏa tất cả các dấu hiệu sau đây: Mức độ suy hô hấp cải thiện. Không xuất hiện bất kỳ dấu hiệu nguy hiểm toàn thân nào. Không xuất hiện bất kỳ biến chứng nào: tràn khí màng phổi, tràn dịch màng phổi, áp xe phổi, nhiễm trùng huyết, sốc nhiễm trùng.

Xử lý số liệu: Phiếu thu thập số liệu sau khi thu thập đầy đủ dữ liệu sẽ được mã hóa theo thứ tự và nhập vào chương trình quản lý số liệu SPSS 22.0.

$\boldsymbol{Y}$ đức: Nghiên cứu chúng tôi tuân thủ nguyên tắc đạo đức về tôn trọng, lợi ích và công bằng đối với con người. Chúng tôi tiến hành nghiên cứu sau khi được sự phê duyệt của hội đồng $Y$ đức của Bệnh viện Bệnh Nhiệt Đới, thành phố Hồ Chí Minh. Đề tài được sự đồng ý của Bộ môn Nhi trường Đại học Y Y khoa Phạm Ngọc Thạch, thành phố Hồ Chí Minh.

\section{KẾT QUẢ NGHIÊN CỨU}

Từ tháng $10 / 2019$ đến $10 / 2020$ có 120 trẻ từ 1 tháng đến 59 tháng được chẩn đoán viêm phổi nặng điều trị tại khoa Nhi $D$ Bệnh viện Bệnh Nhiêt Đới, thành phố Hồ Chí Minh. Trong đó, 36 bệnh nhi có tiêu chí loại trừ, còn lại 84 bệnh nhi được chọn vào nghiên cứu (44 trẻ nam và 40 trẻ nữ, tỉ lệ nam: nữ là $1,1: 1$ ). Tuổi trung bình của bệnh nhi trong mẫu nghiên cứu là $23 \pm 12$ tháng. Bệnh nhi lớn tuối nhất là 49 tháng, nhỏ nhất là 4 tháng tuổi.

3.1. Điều trị hỗ trợ. Trong nhóm nghiên cứu của chúng tối có $28 / 84$ bệnh nhi $(33,3 \%)$ có chỉ định thở oxy mũi qua cannula do suy hô hấp độ 2. Và 1 trường hợp $(1,2 \%)$ suy hô hấp tiến triển sau 3 ngày thở oxy mũi phải thở NCPAP 2 ngày, sau đó thở máy qua nội khí quản 6 ngày.

Số trường hợp thở oxy qua cannula ngay lúc nhập viện là $18 / 28 \mathrm{ca}$, chiếm $64,3 \%$. Số trường hợp thở oxy qua cannula trong quá trình nằm viện là 10 ca chiếm $35,7 \%$.

Thời gian thở oxy mũi qua cannula trung bình 
là 3,5 2,4 ngày, ít nhất là 1 ngày, nhiều nhất là 10 ngày.

Có 20 trường hợp $(71,4 \%)$ NTA dương tính phải thở oxy mũi, trong đó $14 / 20 \mathrm{ca}(70 \%)$ thở oxy mũi ngay lúc nhập viện, $6 / 20$ (30\%) thở oxy mũi trong quá trình nằm viện.

Có 15 trường hợp $\mathrm{PCR}$ dương tính với virus phải thở oxy mũi, trong đó $10 / 15$ trường hợp $(66,7 \%)$ thơ oxy mũi ngay lúc nhập viện, $5 / 15$ $(33,3 \%)$ thở oxy mũi trong quá trình nằm viện.

Có 8 trường hợp đồng nhiễm vi khuẩn và virus phải thở oxy mũi. Trong đó, 6 trường hợp (75\%) thở oxy mũi ngay lúc nhập viện, 2/8 (25\%) thở oxy mũi trong quá trình nằm viện.

\subsection{Kháng sinh}

\section{Bảng 0.1. Kháng sinh ban đâu}

\begin{tabular}{|c|c|c|}
\hline Kháng sinh ban đâu & $\begin{array}{c}\text { Tân số } \\
(\mathbf{n = 8 4 )}\end{array}$ & $\begin{array}{c}\text { Tỷ lệ } \\
\mathbf{( \% )}\end{array}$ \\
\hline Ceftriaxone & 78 & 92,8 \\
\hline Cefoperazon/ Sulbactam & 5 & 6 \\
\hline Ceftriaxone+ Vancomycin & 1 & 1,2 \\
\hline
\end{tabular}

Nhận xét: Kháng sinh ban đầu được sử dụng nhiều nhất là Ceftriaxone có 78 trường hợp chiếm 92,8\%. 5 trường hợp (6\%) sử dụng Cefoperazon/ Sulbactam là do trong vòng 1 tháng nay bệnh nhi có từng nhập viện vì viêm phổi nặng và đã dùng kháng sinh tĩnh mạch. 1 trường hợp $(1,2 \%)$ sử dụng phối hợp Ceftriaxone + Vancomycin là do bệnh nhi có tiền sử nang phổi bẩm sinh, trường hợp này cấy NTA dương tính với Corynebacterium propinquum và PCR phết mũi họng dương tính với Rhinovirus.

Bảng 0.2. Diển tiên đáp ứng kháng sinh ban đầu

\begin{tabular}{|c|c|c|}
\hline $\begin{array}{c}\text { Đáp ứng kháng } \\
\text { sinh ban đâu }\end{array}$ & $\begin{array}{c}\text { Tân số } \\
(\mathbf{n = 8 4 )}\end{array}$ & $\begin{array}{c}\text { Tỷ lề } \\
(\mathbf{\%})\end{array}$ \\
\hline Đáp ứng & 80 & 95,2 \\
\hline Không đáp ứng & 4 & 4,8 \\
\hline
\end{tabular}

Nhận xét: Tỉ lệ không đáp ứng với kháng sinh ban đầu là 4,8\% (4 trường hợp) bao gồm: 1 trường hợp cấy NTA dương tính với $\mathrm{H}$. influenzae kháng Ceftriaxone (MIC $=4 \mu \mathrm{g} / \mathrm{ml}$ ) nên đổi sang kháng sinh Meropenem theo kháng sinh đồ. 2 trường hợp dương tính với S.aureus MRSA nên được thêm kháng sinh Vancomycin theo kháng sinh đồ. Và 1 trường hợp không tìm được tác nhân vi sinh nhưng lâm sàng diễn tiến nặng nên phải đổi kháng sinh 3 lần (Ceftriaxone 3 ngày $\rightarrow$ Cefoperazon/ Sulbactam 2 ngày $\rightarrow$ Meropenem + Vancomycin 7 ngày $\rightarrow$ Thêm Colistin 1 ngày $\rightarrow$ Tử vong). Thời gian dùng kháng sinh trung bình là $6,7 \pm 2,4$ ngày, ngắn nhất là 3 ngày, dài nhất là 21 ngày.

Bảng 0.3. Xuống thang kháng sinh

\begin{tabular}{|c|c|c|}
\hline $\begin{array}{c}\text { Xuống thang } \\
\text { kháng sinh }\end{array}$ & $\begin{array}{c}\text { Tân số } \\
(\mathbf{n = 8 4 )}\end{array}$ & Tỷ lệ (\%) \\
\hline Có & 18 & 21,4 \\
\hline Không & 66 & 78,6 \\
\hline
\end{tabular}

Nhận xét: Nghiên cứu chúng tôi ghi nhận 18 trường hợp có xuống thang kháng sinh chiếm $21,4 \%$. Các trường hợp này xuống thang kháng sinh theo kháng sinh đồ.

Bảng 0.4. Kết quả điều trị

\begin{tabular}{|c|c|c|}
\hline $\begin{array}{c}\text { Kết quả điều } \\
\text { trị }\end{array}$ & $\begin{array}{c}\text { Tân số } \\
\text { (n=84) }\end{array}$ & Tỷ lệ (\%) \\
\hline Thành công & 73 & 86,9 \\
\hline Thất bại & 11 & 13,1 \\
\hline
\end{tabular}

Nhân xét: Trong 11 trường hợp thất bai điều trị thì có 9 trường hợp là tăng mức độ suy hô hấp đơn thuần, 1 trường hợp vừa tăng mức độ suy hô hấp vừa có biến chứng tràn dịch màng phổi, 1 trường hợp vừa tăng mức độ suy hô hấp vừa có biến chứng sốc nhiễm trùng.

Bảng 0.5. Thời gian nằm viện

\begin{tabular}{|c|c|c|}
\hline & $\begin{array}{c}\text { TB } \pm \text { SD (min, } \\
\text { max) (ngày) }\end{array}$ & T test \\
\hline Thành công & $8 \pm 3(5,25)$ & \multirow{2}{*}{$\mathrm{P}>0,05$} \\
\hline Thất bại & $9 \pm 2,5(7,15)$ & \\
\hline
\end{tabular}

Nhận xét: Thời gian nằm viện trung bình của nhóm thành công và nhóm thất bại điều trị khác nhau không ý nghĩa ( $T$ test, $p>0,05$ ).

3.3. Tử vong. Tî lệ tử vong của bênh nhi viêm phổi nặng trong nghiên cứu của chúng tôi là $1,2 \%$.

3.4. Các yếu tố liên quan đến kết quả điêu trị

Bảng 0.6. Phân tích đa biến các yếu tố liên quan đến kêt quả điều trị $(n=84)$

\begin{tabular}{|c|c|c|c|c|}
\hline Yếu tố & OR & $\begin{array}{c}\text { Khoảng tin } \\
\text { cậy 95\% }\end{array}$ & Kiểm định & $\mathbf{P}$ \\
\hline Tiếp xúc người ho/ số mũi & 9 & $1,1-78,5$ & $\chi 2-$ Test & 0,04 \\
Bệnh nền & 17,4 & $1,4-217,4$ & $\chi 2-T e s t$ & 0,02 \\
Không đáp ứng với kháng sinh ban đầu & 10,1 & $0,4-247,3$ & $\chi 2-T e s t$ & 0,2 \\
CRP & 0,9 & $0,9-1,1$ & $\chi 2-T e s t$ & 0,06 \\
Bạch cầu máu & 1 & 1 & $\chi 2-T e s t$ & 0,6 \\
\hline
\end{tabular}

Kết quả phân tích đa biến cho thấy chỉ còn 2 yếu tố độc lập ảnh hưởng đến kết quả điều trị:

Yếu tố bênh nền. Yếu tố tiếp xúc với người ho/ sổ mũi trong tuần qua. Trẻ có bệnh nền có tỉ lệ 
điêu trị thành công thấp hơn nhóm không có bệnh nền $(O R=17,4, P<0,05)$.

\section{BÀN LUÂN}

Trong nhóm nghiên cứu của chúng tôi có 28/84 bệnh nhi $(33,3 \%)$ có chỉ định thở oxy mũi qua cannula do suy hô hấp độ 2 . Và 1 trường hợp $(1,2 \%)$ suy hô hấp tiến triển sau 3 ngày thở oxy mũi phải thở NCPAP 2 ngày, sau đó thở máy qua nội khí quản 6 ngày. Số trường hợp thở oxy qua cannula ngay lúc nhập viện là $18 / 28$ ca, chiếm $64,3 \%$. Số trường hợp thở oxy qua cannula trong quá trình nằm viện là 10 ca chiếm $35,7 \%$.

Trong nghiên cứu chúng tôi, tất cả các trẻ đều được điều trị kháng sinh tĩnh mạch ngay lúc nhập viện. Kháng sinh ban đầu thường gặp nhất là Ceftriaxone (đơn trị) có 78 trường hợp chiếm $92,8 \%$. Kết quả chúng tôi tương đương với tác giả Cao Phạm Hà Giang, Ceftriaxone chiếm 90,2\% kháng sinh ban đầu [1]. Cephalosporin thế hệ 3 được khuyến cáo sữ dụng khi trẻ không được chủng ngửa đầy đủ, nhiễm trùng đe dọa mạng sống, có biến chứng tràn mủ màng phổi hoặc nằm trong vùng có sự đề kháng Penicillin cao.

Trong nghiên cứu có 5 trường hợp được sử dụng dụng Cefoperazon/ Sulbactam là do trong vòng 1 tháng nay bệnh nhi có từng nhập viện vì viêm phổi nặng và đã dùng kháng sinh tĩnh mạch. Cefoperazone là một cephamycin thế hệ thứ ba với hoạt tính kháng khuẩn phổ rộng và khả năng thấm qua màng tế bào vi khuẩn, có hoạt tính chống lại các mầm bệnh đa kháng thường gặp đối với viêm phổi mắc phải tại bệnh viện (HAP) và viêm phổi liên quan đến vấn đề chăm sóc (HCAP). Trong 1 nghiên cứu đối chứng cho thây các tác dụng ngoại ý nghiêm trọng rất hiếm và không có tác dụng phụ nào được đánh giá là có liên quan đến thuốc nghiên cứu. Cefoperazone-sulbactam liều $2 \mathrm{~g}$ mỗi 12 giờ không thua kém cefepime $2 \mathrm{~g}$ mỗi 12 giờ cho bệnh nhân HCAP [5].

Nghiên cứu ghi nhận có 80 trường hợp $(95,2 \%)$ đáp ứng với kháng sinh ban đầu. Trong số những trường hợp diễn tiến tốt này, có 40 trường hợp viêm phổi vi trùng ( cấy NTA dương tính), kháng sinh đồ ghi nhận nhạy $\mathrm{C} 3$, chỉ có 1 trường hợp $H$. influenzae kháng $\mathrm{C} 3$ phải đổi Meropenem và 2 trường hợp dương tính với S.aureus MRSA nên được thêm kháng sinh Vancomycin. Còn lại 40 trường hợp còn lại cấy NTA không mọc vi trùng nhưng vẫn đáp ứng tốt với kháng sinh ban đầu, có thể giải thích được là do những trường hợp này có thể chỉ nhiếm tác nhân siêu vi. Trong nghiên cứu chúng tôi chỉ làm
PCR 6 loại virus nên có thể không phát hiện được các tác nhân siêu vi hô hấp khác. Tuy nhiên, việc $\mathrm{C} 3$ có tỷ lệ đáp ứng trên lâm sàng khá cao gợi ý nên tiếp tục sử dụng C3 như là kháng sinh ban đầu trong điều trị viêm phổi. Nghiên cứu của Cao Phạm Hà Giang ghi nhận có $71,3 \%$ đáp ứng với kháng sinh ban đầu [1].

Trong nghiên cứu chúng tôi có 7 trường hợp thất bại điều trị sau 48 giờ nhưng vẫn không đổi kháng sinh là do kết quả định danh vi khuẩn có rất sớm, thông thường sau 24 giờ, và kháng sinh đồ có sau 72 giờ, nên trên thực tế lâm sàng chúng tôi vẫn chờ kết quả kháng sinh đồ đồng thời kết hợp lâm sàng mới quyết định có đổi kháng sinh hay không, chứ không đổi kháng sinh ngay ở thời điểm 48 giờ.

Gần như tất cả các trẻ đều đáp ứng với điều trị chỉ có 1 trường hợp tử vong và không định danh được tác nhân gây bệnh. Các yếu tố nguy cơ liên quan tử vong trong một nghiên cứu ở Malawian, châu Phi gồm giới nữ, tuổi nhỏ, việm phổi rất nặng, lâm sàng nghi nhiễm Pneumocystis jirovecii, suy dinh dưỡng cấp nặng, bệnh kéo dài hơn 21 ngày, và chuyển đến từ trung tâm khác. Thời gian điều trị trong nghiên cứu có trung bình là 8 ngày. Thời gian điêu trị của tác giả Cao Phạm Hà Giang là $14,3 \pm 10,7$ ngày [1]. Có sự khác biệt này do đối tượng nghiên cứu của Cao Phạm Hà Giang trên viềm phổi nặng trên cơ địa có nhiều bệnh nền (tim bẩm sinh, mềm sụn khí quản, chậm phát triển tâm vận, di chứng não...) nên thời gian điêu trị kéo dài hơn. Trong nghiên cứu chúng tôi có 5 trường hợp có số ngày điều trị $\geq 14$ ngày bao gồm 2 trường hợp tụ cầu dùng kháng sinh tĩnh mạch kéo dài (1 ca dùng 14 ngày và $1 \mathrm{ca}$ dùng 21 ngày), 1 trường hợp Acinetobacter (kháng sinh 10 ngày nhưng bé bị tiêu chảy kéo dài nên nằm viện tới ngày thứ 15), 1 trường hợp nhiễm Corynebacterium propinquum (cơ địa nang phổi bẩm sinh), 1 trường hợp nhiễm S.pneumoniae (nhiễm EBV đi kèm).

Tỉ lệ điều trị thành công là $73 / 84$ trường hợp (chiếm $86,9 \%$ ), thất bại điều trị là $13,1 \%$. Tất cả các ca thất bại điều trị đều do suy hô hấp không cải thiện hoặc xấu đi, trong đó có 1 trường hợp vừa suy hô hấp xấu đi kèm biến chứng sốc nhiễm trùng và tử vong.

\section{KẾT LUÂNN}

Đặc điểm điều trị: Kháng sinh ban đầu: Ceftriaxone 92,8\%, Cefoperazon/ Sulbactam $(6 \%)$, phối hợp Ceftriaxone + Vancomycin $(1,2 \%)$. Diễn tiển đáp ứng kháng sinh ban đầu: 
đáp ứng 95,2\%. không đáp ứng 4,8\%, phải thêm hoặc đổi kháng sinh.

Kết quả điều trị: Thành công 86,9\%, thất bại $13,1 \%$.

Các yếu tố liên quan đến kết quả điều tri: Trẻ có bệnh nền có tỉ lệ điều trị thành công thấp hơn nhóm không có bệnh nền $(O R=17,4, P<0,05)$. Trẻ có tiền căn tiếp xúc với người ho/ số mũi trong tuần qua có tỉ lệ điều trị thành công thấp hơn nhóm không tiếp xúc $(\mathrm{OR}=9, \mathrm{P}<0,05)$.

\section{TÀI LIÊU THAM KHẢO}

1. Giang CPH (2014), Đăc điểm lâm sàng, vi sinh và điểu trị của trẻ em viềm phổi nặng cần thở oxy tại bệnh viện Nhi Đồng 2, Luận văn tốt nghiệp Bác sĩ Nội trú, Đaai Hoc Y Dược TP Hồ Chí Minh, pp.

2. Harris $M$, Clark J, Coote $N$, et al. (2011), British Thoracic Society guidelines for the management of community acquired pneumonia in children: update 2011, Thorax, 66 Suppl 2(pp. ii1-23.
3. Jain DL, Sarathi V, Jawalekar S (2013), Predictors of treatment failure in hospitalized children [3-59 months] with severe and very severe pneumonia, Indian Pediatr, 50(8), pp. 787-9.

4. Jiang W, Wu M, Zhou J, et al. (2017), Etiologic spectrum and occurrence of coinfections in children hospitalized with community-acquired pneumonia, BMC Infect Dis, 17(1), pp. 787.

5. Liu JW, Chen YH, Lee WS, et al. (2019), Randomized Noninferiority Trial of CefoperazoneSulbactam versus Cefepime in the Treatment of Hospital-Acquired and Healthcare-Associated Pneumonia, Antimicrob Agents Chemother, 63(8), pp.

6. Igor Rudan aCB-P, b Zrinka Biloglav, C Kim Mulhollandd \& Harry Campbelle (2008), Epidemiology and etiology of childhood pneumonia, Bulletin of the World Health Organization 86(5), pp. 408-416.

7. WHO (2005), Hospital care for children Guidelines for the management of common childhood illnesses, Second edition, pp. pp. 80-91.

\title{
SO SÁNH HIÊU QUẢ LÀM SACCH DẠ DÀY BẰNG EPUMISAN TRONG CHUẨN BI NGƯỜI BẾNH NộI SOI TIÊU HÓA TRÊN TẠI TRUNG TÂM NộI SOI - BỆNH VIỆN ĐẠI HỌC Y HÀ NộI
}

\author{
Đào Viết Quân*, Lê Quang Hưng*, Hoàng Cẩm Tú*, \\ Đỗ Thị Việt Phương*, Trần Đình Thảo*, Đào Văn Long*
}

\section{TÓM TẮT}

Mục tiêu: Đánh giá hiệu quả làm sạch dạ dày bằng Ėpumisan trong chuẩn bị người bệnh nội soi tiêu hóa trên tại Trung tâm nội soi bệnh viện đại học Y Hà Nội năm 2020-2021. Đối tượng và phương pháp nghiên cứu: Các người bệnh ngoại trú có chỉ định nội soi đường tiêu hóa trên được phẩn ngẫu nhiên vào 2 nhóm: nhóm sử dung Epumisan(Simethicone) và nhóm chứng không sử dụngchấtlàm tan bọt từ tháng 3/2020 tới tháng 3/2021 theo phương pháp thử nghiệm lâm sàng đối chứng ngẫu nhiên. Tất cả cuộc nội soi đều được thực hiện bằng máy nội soi tiêu hóa trên Fujinon, và đánh giá kết quả theo thang điểm của Mc Nally. Kết quả: 1040 người bênh đáp ứng tiêu chuẩn được đưa vào nghiên cứu. Tỷ lệ người bệnh có sử dụng Ėpumisan(Simethicone) có hiệu quả tan bọ ở mức độ $\mathrm{A}$ theo thang $\mathrm{Mc}$ Nally cao hơn hẳn so với nhóm chứng không sử dụng với $p<0,001$. Kết luận: Chuẩn bị nội soi tiêu hóa trên bằng Espumisan làm giảm ứ đọng bot ở thực quản, dạ dày và hành tá tràng một cách hiệu quả, giúp quan sát, định hướng chẩn đoán các tổn thương nhỏ rô ràng, chính xác hơn.

*Trung tâm Nọi soi - Bệnh viện Đại học Y Hà Nội Chịu trách nhiệm chính: Đào Viết Quấn

Email: quandv0083@hmuh.vn

Ngày nhận bài: 5.3.2021

Ngày phản biên khoa học: 27.4.2021

Ngày duyệt bài: 11.5.2021
Tư khóa: Espumisan, Simethicone, nội soitiêu hóa trên, tan bọt

\section{SUMMARY}

\section{COMPARISON EFFECTS OF CLEANING} STOMACH BY EPUMISAN IN PREPARATION OF SUPER GASTROINTESTINAL ENDOSCOPY PATIENTS AT ENDOSCOPIC CENTER - HANOI MEDICAL UNIVERSITY HOSPITAL

Objectives: To evaluate the effect of foam cleaning of Espumisan (Simethicone) in patients with upper gastrointestinal endoscopy at Hanoi Medical University Hospital. Methods: Outpatients with indications for upper gastrointestinal endoscopy were randomly assigned to 2 groups: the Simethicone (Espumisan) and the control group, from March 2020 to March 2021, by the method of randomized controlled clinical trial. All endoscopy was performed using a gastrointestinal endoscopy on Fujinon, and evaluated the results on a scale of Mc Nally. Results: 1040 patients who met the criteria were included in the study. The percentage of level A (complete bubble cleaniness) in esophagus, stomach body, fundus, antrum, and duodenum of patients using Espumisan are higher than those of control group ( $p<0.00001)$. Conclusion: The preparation of upper gastrointestinal endoscopy with Espumisan reduces the stagnation of foam in the esophagus, stomach and duodenum effectively, helping to observe and 